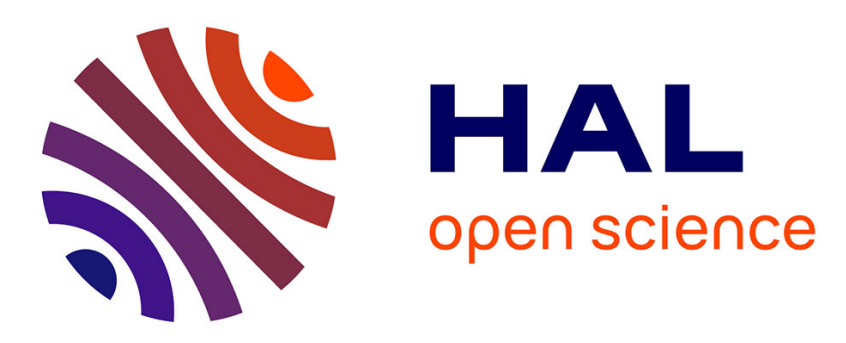

\title{
Biomechanical Modeling to Prevent Ischial Pressure Ulcers
}

\author{
Vincent Luboz, Marion Petrizelli, Marek Bucki, Bruno Diot, Nicolas \\ Vuillerme, Yohan Payan
}

\section{To cite this version:}

Vincent Luboz, Marion Petrizelli, Marek Bucki, Bruno Diot, Nicolas Vuillerme, et al.. Biomechanical Modeling to Prevent Ischial Pressure Ulcers. Journal of Biomechanics, 2014, pp.1-23. 10.1016/j.jbiomech.2014.05.004 . hal-00996034

\section{HAL Id: hal-00996034 https://hal.science/hal-00996034}

Submitted on 26 May 2014

HAL is a multi-disciplinary open access archive for the deposit and dissemination of scientific research documents, whether they are published or not. The documents may come from teaching and research institutions in France or abroad, or from public or private research centers.
L'archive ouverte pluridisciplinaire HAL, est destinée au dépôt et à la diffusion de documents scientifiques de niveau recherche, publiés ou non, émanant des établissements d'enseignement et de recherche français ou étrangers, des laboratoires publics ou privés. 


\section{Biomechanical Modeling to Prevent Ischial Pressure Ulcers}

2 Vincent Luboz ${ }^{1}$, Marion Petrizelli ${ }^{1}$, Marek Bucki ${ }^{2}$, Bruno Diot $^{3}$, Nicolas

3 Vuillerme ${ }^{4}$, Yohan Payan ${ }^{1}$

4

$5{ }^{1}$ UJF-Grenoble1/CNRS/TIMC-IMAG UMR 5525, Grenoble, F-38041, France, \{vluboz, 6 ypayan\}@imag.fr;

$7 \quad 2$ TexiSense, Montceau-les-Mines, France, marek.bucki@ texisense.com;

$8{ }^{3}$ IDS, Montceau-les-Mines, France, \& Univ. Grenoble Alpes, Laboratoire AGIM FRE 3405

9 CNRS/UJF/UPMF/EPHE, La Tronche, France, b.diot@ids-assistance.com;

$10{ }^{4}$ Univ. Grenoble Alpes, Laboratoire AGIM FRE 3405 CNRS/UJF/UPMF/EPHE, La Tronche, 11 France \& Institut Universitaire de France, Nicolas.Vuillerme @ agim.eu

\section{Corresponding author:}

14 Yohan Payan

15 Equipe GMCAO - Laboratoire TIMC-IMAG

16 Université Joseph Fourier - CNRS UMR 5525

17 Pavillon Taillefer

18 Faculté de Médecine - 38706 La Tronche cedex - France

19 Tel: +33 (0)4 56520001 - Fax: +33(0)4 56520055

20 email: yohan.payan@imag.fr

Keywords: pressure ulcer prevention, biomechanical model, stiffness influence, spinal cord 23 injury. 


\section{Abstract}

28 With 300,000 paraplegic persons only in France, ischial pressure ulcers represent a major 29 public health issue. They result from the buttocks' soft tissues compression by the bony 30 prominences. Unfortunately, the current clinical techniques, with - in the best case 31 embedded pressure sensor mats, are insufficient to prevent them because most are due to high 32 internal strains which can occur even with low pressures at the skin surface. Therefore, improving prevention requires using a biomechanical model to estimate internal strains from

34 skin surface pressures. However, the buttocks' soft tissues' stiffness is still unknown. This 35 paper provides a stiffness sensitivity analysis using a finite element model. Different layers 36 with distinct Neo Hookean materials simulate the skin, fat and muscles. With Young moduli 37 in the range [100 - $500 \mathrm{kPa}$ ], [25 - $35 \mathrm{kPa}$, and [80 - $140 \mathrm{kPa}$ ] for the skin, fat, and muscles 38 respectively, maximum internal strains reach realistic 50 to $60 \%$ values. The fat and muscle 39 stiffnesses have an important influence on the strain variations, while skin stiffness is less influent. Simulating different sitting postures and changing the muscle thickness also result in

41 a variation in the internal strains. 
44

45

\section{Introduction}

With more than 300,000 paraplegic persons only in France among which $80 \%$ will develop a pressure ulcer in their life because they do not change posture by reflex, preventing ischial pressure ulcer is critical. Pressure ulcers start at the interface between bones and soft tissues underneath an intact skin and advance outwards rapidly causing substantial subcutaneous damages before being visible at the skin surface. Usual prevention in the clinical routine consists in using cushions to reduce the pressure below the patients' buttocks and regularly changing their sitting posture. This procedure is not always effective as it demands a constant monitoring. When prevention fails, pressure ulcers develop and patients must stay in bed for months before healing and/or undergo heavy surgery.

Measuring surface pressures can help in alerting users against skin injuries (Pipkin and Sprigle, 2008), but these measurements cannot predict dangerous internal tissue loadings (Linder-Ganz et al., 2008) responsible for most of the deep pressure ulcers. For example, a similar pressure map may be observed under the buttocks of a heavy paraplegic person with sharp ischial tuberosity (IT) and a thin person with blunt ITs; however, deep pressure ulcer formation depends on the IT curvature as well as the thickness of the soft tissues (Sopher et al., 2010). Quantitatively estimating the internal strains from the interface pressures while taking into account the anatomical variability is only possible by (1) building a patientspecific biomechanical model of the soft tissues/bony prominence and (2) using this numerical model to compute the internal strains (Elsner and Gefen, 2008, Loerakker et al., 2011).

Several biomechanical models of the gluteal region have already been proposed. (LinderGanz et al., 2009) proposed a 2D biomechanical model using a Neo Hookean constitutive law 
67 for the muscles $(E=31 \mathrm{kPa}, v=0.49)$ and the other soft tissues $(\mathrm{E}=9 \mathrm{kPa}, v=0.49)$ to 68 evaluate the internal strains in the buttocks of a paraplegic patient. This study was completed

by a MRI analysis (Shabshin et al., 2010) of several patients and showed an average maximal internal strain of $72 \%$ for the muscles and $35 \%$ for the fat tissues when the subjects sit on a rigid chair. While sitting on a softer material (foam), the average maximal internal strain decreases to $64 \%$ for the muscles and to $23 \%$ for the fat tissues. (Oomens et al., 2003) presented a $2 \mathrm{D}$ biomechanical model of the buttock with a simplified ischium and three layers of tissues (skin, fat and muscles) modeled with an Ogden material $\left(\alpha_{\text {skin }}=10, \mu_{\text {skin }}=8 \mathrm{kPa}\right.$, $\left.\alpha_{\mathrm{fat}}=5, \mu_{\mathrm{fat}}=10 \mathrm{kPa}, \alpha_{\text {muscle }}=30, \mu_{\text {muscle }}=3 \mathrm{kPa}\right)$. The simulation showed that the maximal internal strain, when lying on a cushion, was below the IT in the fat layer. Another study from (Verver et al., 2004) used a Neo Hookean constitutive law to model the skin $(E=150 \mathrm{kPa}, \mathrm{v}=$ 0.46) and a Mooney Rivlin constitutive law to model the other soft tissues $\left(\mathrm{A}_{1}=1.65 \mathrm{kPa}\right.$, $\left.\mathrm{A}_{2}=3.35 \mathrm{kPa}, v=0.49\right)$ in a $3 \mathrm{D}$ biomechanical model. It showed that the pressure distribution depends on the stiffness of the chair cushion, on the stiffness of the buttocks' soft tissues, and on the posture of the subject. A three-value sensitivity analysis of the stiffness was performed for the soft tissue layer (muscle and fat combined), showing some influences on the resulting stresses.

It appears that the literature has proposed many values for stiffness parameters as well as various modeling hypotheses (homogeneous model, different layers with or without the skin...) from one study to the other. In order to quantify these differences, this paper presents a sensitivity analysis of the buttocks soft tissues' stiffness using a 3D biomechanical model of the gluteal soft tissues in sitting position. The study separates the soft tissues in different materials for each of the three layers of the buttocks: skin, fat, and muscles. The mechanical parameter ranges are defined iteratively. The algorithm starts with the values found in the literature and refines them in order to obtain an average deformation between $50 \%$ and $60 \%$, 
considering the range of maximal internal VM strains observed in the literature (Linder-Ganz et al., 2009, Oomens et al., 2003, Shabshin et al., 2010, Verver et al., 2004), within a patientspecific model. The second part of the study focuses on two different sitting postures and on the influence of the muscle layer thickness.

\section{Materials and Methods}

The first step of this study is to build the finite element (FE) mesh from a dataset. The boundary conditions are defined before specifying the different material properties applied to the buttocks soft tissues. The modeling and simulation are performed within the ArtiSynth open source framework (Lloyd et al., 2012) (www.artisynth.org).

a. Creation of the finite element mesh

The anatomy of our model is extracted from the dataset of a young healthy male subject (38 years old, $100 \mathrm{Kg}$ and $1.90 \mathrm{~m}$ ). The subject's CT exam (image size 512x512x403, and resolution $0.97 \times 0.97 \times 1 \mathrm{~mm}^{3}$, fig. 1d) was semi-automatically segmented to acquire the external surfaces of the skin, the muscles and the bones, using the ITK-Snap software's snake segmentation (Yushkevich et al., 2006). Because the subject was lying on his right side (which was therefore compressed), only his left buttock was segmented. The right side was reconstructed by symmetry. The muscles were segmented as a single entity as it was too difficult to separate them on the dataset.

Using an automatic hexahedrons-dominant FE mesh generator (Lobos et al., 2010), the segmented skin surface was filled with finite elements as illustrated in fig 1a. Because we assume the bones to be rigid, they are represented as non-deformable solids. The different layers are also taken into account by this mesh generator which creates a finite element mesh 
with clear and precise boundaries between each of them, fig. $1 \mathrm{~b}$ and $\mathrm{c}$. The mesh is composed of 164,690 linear elements (including 45,374 hexahedrons, 40,470 pyramids, 54,778 tetrahedrons, and 24,068 wedges) and 89,136 nodes.

\section{b. Boundary conditions}

In our simulation, gravity is not taken into account since it was shown that its influence is limited when buttocks are in a sitting configuration (there is at least a 100 fold difference between the influence of the subject weight on the whole buttocks and the influence of the gravity when applied to those tissues). The finite element nodes at tissue/bone interface are fixed, fig. $1 \mathrm{~b}$ and $\mathrm{c}$, as a no sliding binding between the soft tissues and the bones is assumed.

The model is subject to a set of pressures measured with a commercial pressure sensor (www.zebris.de, with 50x51 sensors of $0.8 \mathrm{~cm}^{2}$ each). The subject was sitting on the sensor with the feet not touching the ground and his back not on the chair rest so that all his weight was on the pressure sensor, his arms crossed on his chest. The recorded pressure map is

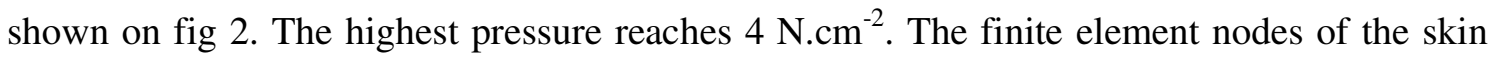
surface are orthogonally projected onto this pressure map to determine the pressure values for each of them. To ensure the convergence of the simulation this pressure is applied as a linear ramp from $0 \%$ of the pressure at $0.1 \mathrm{~s}$ to $100 \%$ of the pressure at $1.1 \mathrm{~s}$. The pressure is applied along the normal at each of the nodes and taking into account the surface of the neighboring elements. These normal and surface are recomputed at each time step.

\section{c. Buttocks model}

In order to enhance the anatomical realism of the model, the three main soft structures of the buttocks are considered for the finite element model, namely the skin, fat, and muscles. Fig $1 \mathrm{~b}$ and $\mathrm{c}$ show cross sections of the mesh after identifying these structures. There are 
83,001 elements in the fat layer, 73,623 in the muscle layer and 8066 in the skin layer. The first step consists of representing the skin as a thin layer of elements at the outer surface of the finite element mesh built in section 2.a. This $1.5 \mathrm{~mm}$ layer (Hendriks et al., 2006) is extruded from the finite element mesh. It results in a 1-element thick layer representing the skin.

In a second step, the elements representing the muscle layer, fig $1 \mathrm{~b}$ and $\mathrm{c}$, are identified by finding the elements of the finite element mesh located inside the muscle surface segmented from the medical dataset. Finally, the elements between the skin layer and the muscle layer are considered as fat tissues.

These three layers are modeled using a compressible Neo Hookean constitutive material (Bonnet \& Wood, 1997). Such material exhibits characteristics that can be identified with the familiar material parameters found in linear elastic analysis. Its energy function depends on the two Lamé parameters and can also be expressed as a function of the shear and bulk modulus as well as a function of the Young modulus $E$ and Poisson's ratio $v$ (see Bonnet \& Wood, 1997 for details). We have chosen in this paper to provide $E$ and $v$ values so that the material can be compared with other constitutive materials proposed in the literature. Since the main objective of our study was to provide a sensitivity analysis as concerns the tissues' stiffness (modeled with the Young modulus), a fixed value of 0.49 was assumed for the Poisson's ratio. This value was already proposed by other groups (Linder-Ganz et al., 2009, Verver et al., 2004) since it has the advantage of representing the quasi-incompressibility for the buttocks soft tissues. To evaluate the influence of the stiffness parameters of each layer, a sensitivity analysis was carried out by setting the layers' Young moduli to different values ranging from 5 to $40 \mathrm{kPa}$ for the fat layer (every $5 \mathrm{kPa}$ ), from 40 to $160 \mathrm{kPa}$ for the muscles (every $20 \mathrm{kPa}$ ), and from 100 to $500 \mathrm{kPa}$ for the skin (every $100 \mathrm{kPa}$ ). Those values were chosen according to the ones reported in the literature. 

Shabshin et al., 2010, Verver et al., 2004), further simulations are carried out, using the "reference" constitutive parameters derived from the biomechanical model. From this model, a study of the influence of two different sitting postures is performed: in the initial position (with the trunk forming a 110 degree angle with the legs) and in a more upright sitting position (with the body forming a 90 degree angle with the legs). To perform this change of angle, the segmented surface of the skin and bones are deformed using the lattice tool in Blender (blender.org). The same pressure map is applied in both cases.

A second posture test is performed by comparing the initial sitting posture constrained with the initial pressure map, fig 2, and the initial sitting posture constrained with a different pressure map of the same healthy young subject. In this case, the subject's weight is deported to his right side, fig 3 , to simulate unilateral sitting posture. Comparing those two postures allows simulating the change of postures that a paraplegic patient might experience during the day.

Finally, the influence of the thickness of the muscle layer is also considered in the because the subject who participated to the development of our biomechanical model is young and healthy and consequently has a fairly important layer of muscles whereas older and/or paraplegic patients may have thinner muscle layers. 


\section{Results}

As mentioned in the introduction, pressure ulcers are due to high internal strains even though low pressures are measured at the skin surface. The risk of formation of a pressure ulcer should therefore be assessed based on the level of maximal internal strains in the FE mesh. The strain measure commonly used in the literature is the Von Mises (VM) equivalent strain (Linder-Ganz et al., 2008, Oomens et al., 2003). Based on the work of (Loerakker et al., 2011), another criterion, namely the volume of the largest zone with contiguous nodes with VM strains over $20 \%$, was measured during the simulations and is discussed in the appendix.

a. Buttocks model sensitivity analysis

The influence of the Young moduli chosen for the three types of soft tissues is displayed in figure 4 which shows the maximal VM strains below the ischial tuberosities for the 245 simulations made with different Young moduli defined for the skin $\left(E_{\text {skin }}\right)$, fat $\left(E_{\text {fat }}\right)$, and muscle ( $E_{\text {muscle }}$ ) layers. From left to right, the fat Young's modulus varies from $10 \mathrm{kPa}$ to $40 \mathrm{kPa}$. For a given fat Young's modulus, the moduli for the skin and muscle vary respectively from $100 \mathrm{kPa}$ to $500 \mathrm{kPa}$ and from 40 to $160 \mathrm{kPa}$.

An example of a map of the maximal VM strains is given in Figure 5. It shows that they are located below the IT, in the fat layer, close to the muscle/fat interface. This is the case for most of the simulations. It must be noted that occasionally the maximal VM strains are located inside the muscle layer, close to the bone/muscle interface, when the muscles' Young's modulus is close to the fat's Young's modulus, for example when $\left(\mathrm{E}_{\text {muscle }}, \mathrm{E}_{\mathrm{fat}}\right)=(40$ $\mathrm{kPa}, 40 \mathrm{kPa})$ or $\left(\mathrm{E}_{\text {muscle }}, \mathrm{E}_{\mathrm{fat}}\right)=(60 \mathrm{kPa}, 40 \mathrm{kPa})$.

As concerns the Young moduli chosen for the fat, it appears that values below $20 \mathrm{kPa}$ lead to huge strains (more than 100\%), far above the deformations mentioned in the literature. It seems therefore that such values are not realistic. 
Looking at figure 4 in more details, it appears that the strains levels are not very

212

sensitive to the Young moduli chosen for the skin tissues. Indeed, with skin moduli ranging between 100 and $500 \mathrm{kPa}$, there is an average variation of $3.7 \%$ of the $\mathrm{VM}$ strains with a standard deviation of 3.3 percentage points (PPs). The minimum VM strains variation is $0.1 \%$ for $\left(E_{\text {muscle }}, E_{\text {fat }}\right)=(120 \mathrm{kPa}, 40 \mathrm{kPa})$ while the maximum $\mathrm{VM}$ strains variation only reaches $17.1 \%$ for $\left(\mathrm{E}_{\text {muscle }}, \mathrm{E}_{\mathrm{fat}}\right)=(40 \mathrm{kPa}, 10 \mathrm{kPa})$.

On the contrary, the strain sensitivity to the Young's modulus of the muscle is more important with a VM strain variation of $38.5 \%$ with a standard deviation of 15.9 PPs. For

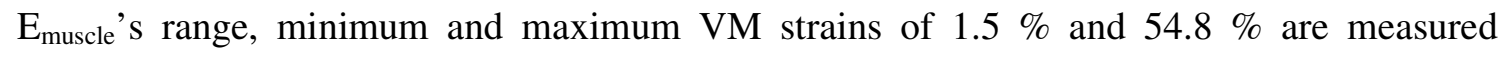
respectively for $\left(\mathrm{E}_{\text {fat }}, \mathrm{E}_{\text {skin }}\right)=(5 \mathrm{kPa}, 500 \mathrm{kPa})$ and $(40 \mathrm{kPa}, 500 \mathrm{kPa})$. Finally, the most sensitive parameter is the Young's modulus of the fat with a strain variation of $71.1 \%$ and a standard deviation of 21.6 PPs. For $\mathrm{E}_{\mathrm{fat}}$ 's range, minimum and maximum VM strains of 22.8 $\%$ and $92.7 \%$ are measured for respectively $\left(\mathrm{E}_{\text {muscle }}, \mathrm{E}_{\mathrm{skin}}\right)=(40 \mathrm{kPa}, 100 \mathrm{kPa})$ and $(160 \mathrm{kPa}$, $100 \mathrm{kPa})$. Overall, it appears that the influence of the skin stiffness can be neglected compared to ones of the fat and muscle, among which the influence of fat stiffness is the most important.

Finally, considering the range of maximal internal VM strains observed in the literature and in Figure 4 (i.e. between $50 \%$ and $60 \%$ ), the following material parameter values could lead to these deformations and are therefore assumed to be realistic: $\mathrm{E}_{\text {skin }}$ in the range [100 - $500 \mathrm{kPa}$ ], $\mathrm{E}_{\mathrm{fat}}$ in the range [25 - $35 \mathrm{kPa}$ ], and $\mathrm{E}_{\text {muscle }}$ in the range [80 - $140 \mathrm{kPa}$ ].

In the rest of the paper, we propose to define a "reference" set of values inside these realistic ranges, namely $\mathrm{E}_{\text {skin }}=200 \mathrm{kPa}, \mathrm{E}_{\text {fat }}=30 \mathrm{kPa}$, and $\mathrm{E}_{\text {muscle }}=100 \mathrm{kPa}$. These values lead to a maximal strain of $57.4 \%$. They will be used as a reference for the simulations provided to study the influence of two different sitting postures and muscle layer thickness.

b. Consequences of the different sitting postures on the internal VM strains 
The two sitting postures described in section 2.d (on one side or sitting upright) are

simulated in order to evaluate their respective effect on the maximal internal strains. As mentioned above, those simulations are performed with the biomechanical model using the "reference" parameters.

When sitting in the upright position, the maximal internal strain observed is $64.1 \%$, which represents an increase of 6.7 VM strain PPs compared to the initial position (a maximal VM strain of $57.4 \%$ was observed at 110 degrees).

When sitting on the right side of the buttocks - a situation represented by the pressure map of fig. 3 - the maximal internal strain observed is $64.2 \%$, which represents an increase of 6.8 VM strain PPs compared to the initial position (where the buttocks are evenly positioned on the platform with an angle of 110 degrees).

c. Effect of the variation of muscle thickness on internal strains

To assess the influence of the thickness of the muscle layer on maximal VM strains, two new biomechanical models were created by reducing the muscle thickness by $10 \mathrm{~mm}$ and $20 \mathrm{~mm}$, as explained in section 2.d. Note that by consequences, the fat layer thickness increases by 10 and $20 \mathrm{~mm}$. Again, the simulations are performed with the "reference" mechanical parameters.

With $10 \mathrm{~mm}$ and $20 \mathrm{~mm}$ muscle layer thinnings, maximal internal VM strains of 71.9 $\%$ and $97.7 \%$ are observed respectively, which represent an increase of 14.5 and 40.3 PPs compared to the initial case. Those maximal strains are again located below the IT, in the fat layer, close to the muscle/fat interface. Of course, because of the reduction of the muscle thickness, this interface is closer to the bony structure than in the initial model. 


\section{Discussion and conclusion}

A subject-specific 3D finite element biomechanical model of the buttocks was introduced to study the influence of material stiffness, soft tissue layers thicknesses and postures onto internal strains. The model is built from the segmentation of a CT scan which provided the surfaces of the skin, muscles and bones. It includes the main structures that constitute the buttock soft tissues, namely the skin, fat and muscles. This model uses a compressible Neo Hookean constitutive law, with a Poisson ratio of 0.49. A wide range of Young moduli was implemented to evaluate the influence of each soft tissue layer $\left(\mathrm{E}_{\mathrm{fat}}=10\right.$ to $40 \mathrm{kPa}, \mathrm{E}_{\text {muscles }}=40$ to $160 \mathrm{kPa}$, and $\mathrm{E}_{\text {skin }}=100$ to $500 \mathrm{kPa}$ ). These evaluations show that the skin layer has little influence on the maximal strains. This is probably due to the fact that this layer is very thin and quite stiff. On the other hand, because of their comparatively large thicknesses and lower stiffnesses, the fat and muscle layers have much more influence. Based on the results for this subject and given the maximal VM strains observed in the literature, a maximal internal strain between 50 and $60 \%$ was assumed to be the most realistic one and was obtained with $\mathrm{E}_{\mathrm{skin}}$ in the range $[100-500 \mathrm{kPa}], \mathrm{E}_{\mathrm{fat}}$ in the range $\left[25-35 \mathrm{kPa}\right.$, and $\mathrm{E}_{\mathrm{muscle}}$ in the range [80 - $140 \mathrm{kPa}$ ]. Furthermore, this sensitivity analysis shows that the maximal VM strains are mainly located below the IT, in the fat layer, close to the muscle/fat interface. This tissue will consequently be suffering the most from pressure ulcers. The maximal VM strains occasionally appear inside the muscle layer, close to the bone/muscle interface, but only when the muscles' Young's modulus is similar to the fat's Young's modulus, which is probably the case for paraplegic or elderly persons.

This study also allowed evaluating the influence of three different sitting postures: sitting with a 110 degree angle between legs and torso (initial posture), sitting with a 90 degree angle between legs and torso (upright), and sitting only on the right side of the buttocks. Simulations showed that sitting in the upright posture increases the maximal internal 
VM strain by 6.7 PPs as compared to $57.4 \%$. This could be explained by the position of the

284 ischial tuberosity: at 90 degrees, the ischia protrude more and probably act more like picks stabbing the soft tissues than in the 110 degree sitting posture. The displacements of the cushioning muscle layer with respect to the more or less protruding ischia, not simulated here, should also be considered as a possible cause. This observation could be different for other subjects because of the distinct morphology of their ischia or different soft tissues layer thicknesses. When sitting on the right side of the buttocks, the maximal internal strain increases by 6.8 PPs compared to the initial posture. This increase is due to the weight transfer on the right side. Intuitively, a larger increase could be expected. This discrepancy can be explained by the fact that the subject's total weight was not only transferred on his right buttocks, but also on his right leg (light blue zone on fig. 3), which is not included in our model. Therefore the recorded pressure pattern does not reflect an unsupported unilateral weight transfer and the resulting strains are probably lower than they should be. This observation indicates that the buttocks model should consequently be extended to include the upper thigh.

Finally, the influence of the muscle layer thickness has been studied by reducing it by 10 and $20 \mathrm{~mm}$. It showed an increase of the maximal internal strains by 14.5 and $40.3 \mathrm{VM}$ strain PPs, respectively. The location of those strains in the fat layer below the ischia indicates that paraplegic patients with a thinner muscle layer or fatter patients might be more likely to develop a pressure ulcer. Again, this has to be verified on more than one subject but this conclusion is in accordance with Gefen and colleagues' studies (Elsner and Gefen, 2008, Sopher et al., 2010).

Overall, using our biomechanical model allows studying the formation of pressure ulcers and could help developing different strategies to prevent them. To this aim, the use of a pressure sensor mat embedded on the patient wheelchair and coupled with a biomechanical 
model seems relevant provided that such a model is able to evaluate in real time the gluteal tissues internal strains and consequently to raise warnings in case of pressure ulcers risks.

Nevertheless, before proposing such pressure ulcer prevention tools for a routine use, several points still need to be improved. The first one is the necessity, for each patient modeled with our method, to automatically import patient-specific data: anatomical surfaces and biomechanical parameters. It is indeed critical to be able to differentiate each tissue layer, especially the skin, muscles, and the bones, as their positions can play a key role in the location of pressure ulcers. Other imaging modalities with corresponding image processing would probably have to be studied to improve this point. Finally, the definition of the patientspecific mechanical parameters will also need to be addressed since soft tissue stiffness, especially for the fat and muscle tissues, impacts significantly the range of internal strains and consequently the risks for pressure ulcer formation. Using elastography (from MRI or Ultrasound) or classical indentation could help in estimating these elastic parameters in vivo. It could also help in defining a more precise Poisson ratio as the value chosen in this study is for now inspired by the literature. A preliminary sensitivity analysis of this parameter indeed showed large variations of the VM strains even with small variations of the Poisson ratio (as pointed in Gefen, 2010).

\section{Acknowledgments}

This work is partly funded by the French national project ANR, under reference ANR-TecSan 2010-013 IDS, by the Institut Universitaire de France, and by French state funds managed by the ANR within the Investissements d'Avenir programme (Labex CAMI), under reference ANR-11-LABX-0004. 
331 Conflict of interest statement: the authors certify that no conflict of interest is raised by this

332 work.

\section{References}

334

Bonet, J., and Wood, R.D., 2008. Nonlinear Continuum Mechanics for Finite Element Analysis. Cambridge University Press.

Elsner, J.J., and Gefen, A., 2008. Is obesity a risk factor for deep tissue injury in patients with spinal cord injury? Journal of Biomechanics, 41:3322-3331.

Gefen A., 2010. The biomechanics of heel ulcers. J Tissue Viability, 19(4):124-31.

Hendriks, F.M., Brokken, D., Oomens, C.W.J., Bader, D.L., and Baaijens, F.P.T., 2006. The relative contributions of different skin layers to the mechanical behavior of human skin in vivo using suction experiments. Medical Engineering \& Physics, 28:259-266.

Strains and stresses in sub-dermal tissues of the buttocks are greater in paraplegics than in 344 healthy during sitting. Journal of Biomechanics, 41:567-580. Finite Element Monitoring of Sub-Dermal Tissue Stresses in Individuals with Spinal Cord Injury: Toward Prevention of Pressure Ulcers, Annals of Biomedical Engineering, 37(2):387400.

Lloyd, J.E., Stavness, I., and Fels, S., 2012. Artisynth: a fast interactive biomechanical 350 modeling toolkit combining multibody and finite element simulation. In: Payan Y. (Ed.), Soft

351 Tissue Biomechanical Modeling for Computer Assisted Surgery, Studies in Mechanobiology, 352 Tissue Engineering and Biomaterials, 11:355-394. 
353 Lobos, C., Payan, Y., and Hitschfeld, N., 2010. Techniques for the generation of 3D Finite

354 Element Meshes of human organs. Informatics in Oral Medicine: Advanced Techniques in

355 Clinical and Diagnostic Technologies. Hershey, PA: Medical Information Science Reference, $356 \quad 126-158$.

357 Loerakker, S., Manders, E., Strijkers, G.J., Nicolay, K., Baaijens, F.P.T., Bader, D.L., 358 Oomens, C.W.J., 2011. The effects of deformation, ischaemia and reperfusion on the 359 development of muscle damage during prolonged loading. Journal of Applied Physiology, 360 111(4): 1168-1177.

Oomens, C.W.J., Bressers, O.F.J.T., Bosboom, E.M.H., Bouten, C.V.C. and Bader, D.L., 362 2003. Can Loaded Interface Characteristics Influence Strain Distributions in Muscle Adjacent 363 to Bony Prominences? Computer Methods in Biomechanics and Biomedical Engineering, 364 6(3):171-180.

Pipkin, L., and Sprigle, S., 2008. Effect of model design, cushion construction, and interface 366 pressure mats on interface pressure and immersion. Journal of Rehabilitation Research \& Development, 45:875-882.

Shabshin, N., Zoizner, G., Herman, A., Ougortsin, V., and Gefen, A., 2010. Use of weight369 bearing MRI for evaluating wheelchair cushions based on internal soft-tissue deformations under ischial tuberosities, Journal of Rehabilitation Research \& Development, 47(1):31-42.

371 Sopher, R, Nixon, J., Gorecki, C., and Gefen, A., 2010. Exposure to internal muscle tissue 372 loads under the ischial tuberosities during sitting is elevated at abnormally high or low body 373 mass indices. Journal of Biomechanics, 43:280-286. 
374 Verver, M.M., van Hoof, J., Oomens, C.W.J., Wismans, J.S.H.M. and Baaijens, F.P.T., 2004.

375 A Finite Element Model of the Human Buttocks for Prediction of Seat Pressure Distributions,

376 Computer Methods in Biomechanics and Biomedical Engineering, 7(4):193-203.

377 Yushkevich, P.A., Piven, J., Hazlett, H.C., Gimpel Smith, R., Ho, S., Gee, J.C., and Gerig, G., 378 2006. User-guided 3D active contour segmentation of anatomical structures: Significantly 379 improved efficiency and reliability. Neuroimage, 31(3):1116-28.

380

381 


\section{Figure captions:}

383 Figure 1. (a) Finite element model of the buttocks, (b) and (c) Frontal and sagittal cross 384 sections showing the three layers of materials defining the buttocks model: skin (in grey), fat 385 (in yellow) and muscles (in red), the bones are represented in white and are simulated as fixed 386 nodes, (d) CT scan slice showing the ischial tuberosity surrounded by muscles and fat tissues.

387 Figure 2. Pressure map measured with the Zebris platform. In this example, the maximum 388 pressure (in red) is 4 N.cm ${ }^{-2}$ due to a non-symmetrical posture of the subject.

389 Figure 3. Pressure map corresponding to the subject's weight being only applied on his right 390 side. The maximal pressure reaches $5 \mathrm{~N} \cdot \mathrm{cm}^{-2}$ (in red).

391 Figure 4. Evolution of the maximal internal strain as a function of the Young moduli chosen 392 for the skin, fat, and muscle tissues.

393 Figure 5. The $57.4 \%$ maximal Von Mises strains (red dots) are mainly located in the fat layer 394 under the ischial tuberosities at the interface with the muscle layer: (a) view from the back, 395 (b), view from the side. 
399
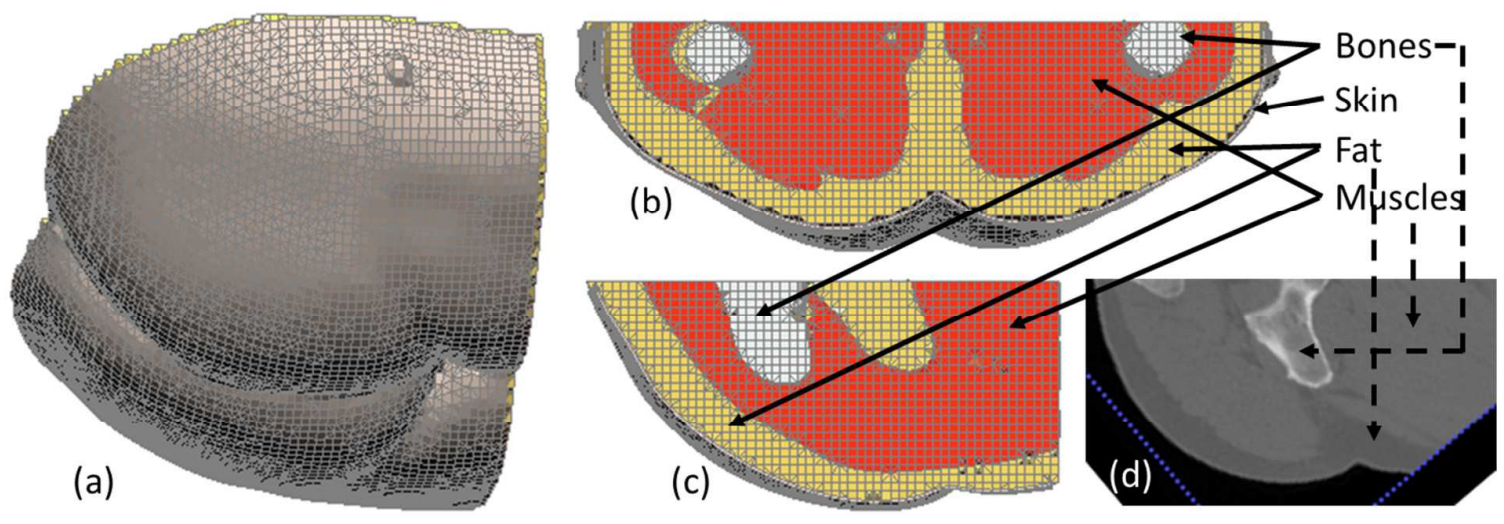

400

Figure 1

401 


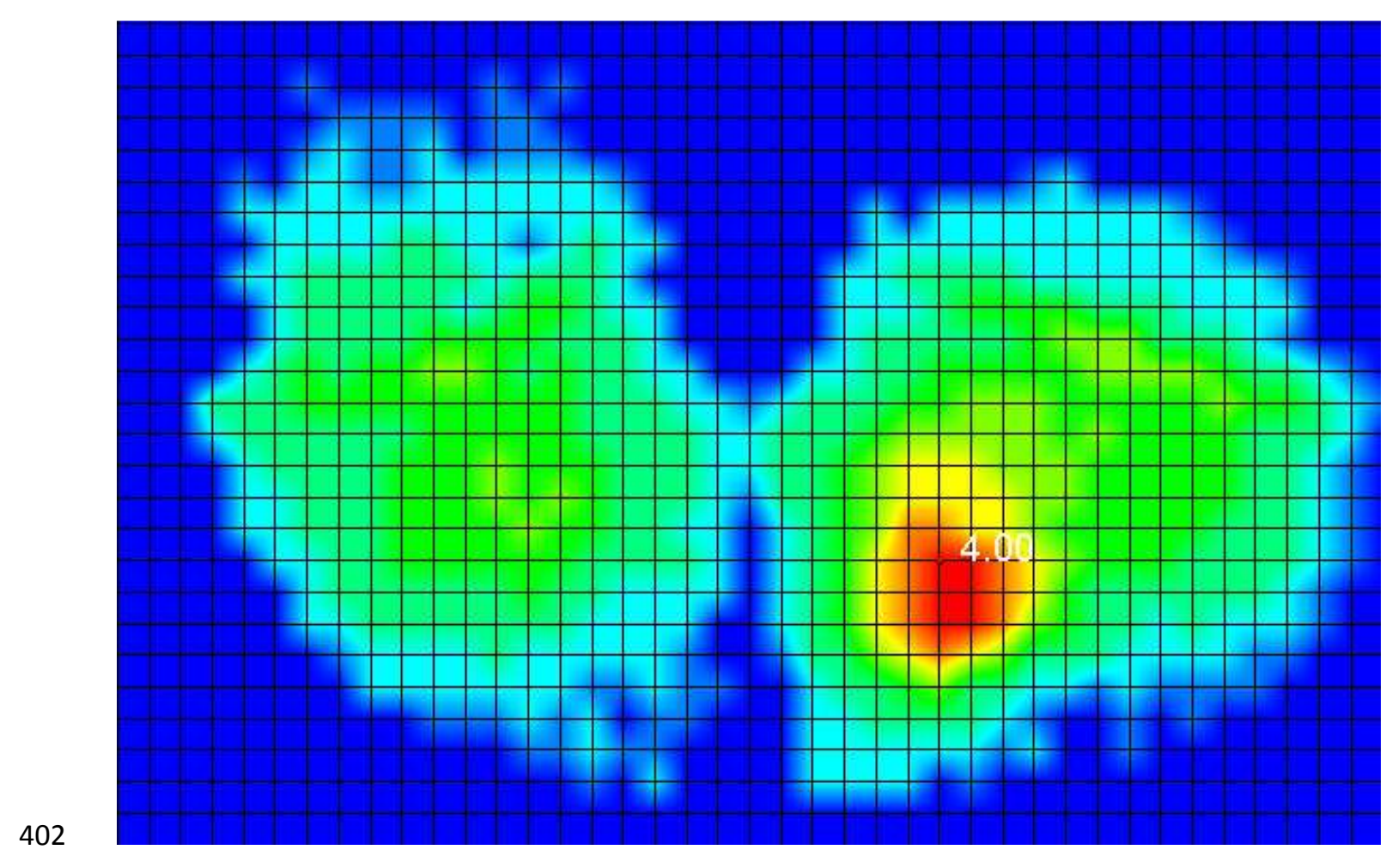

$403 \quad$ Figure 2

404 


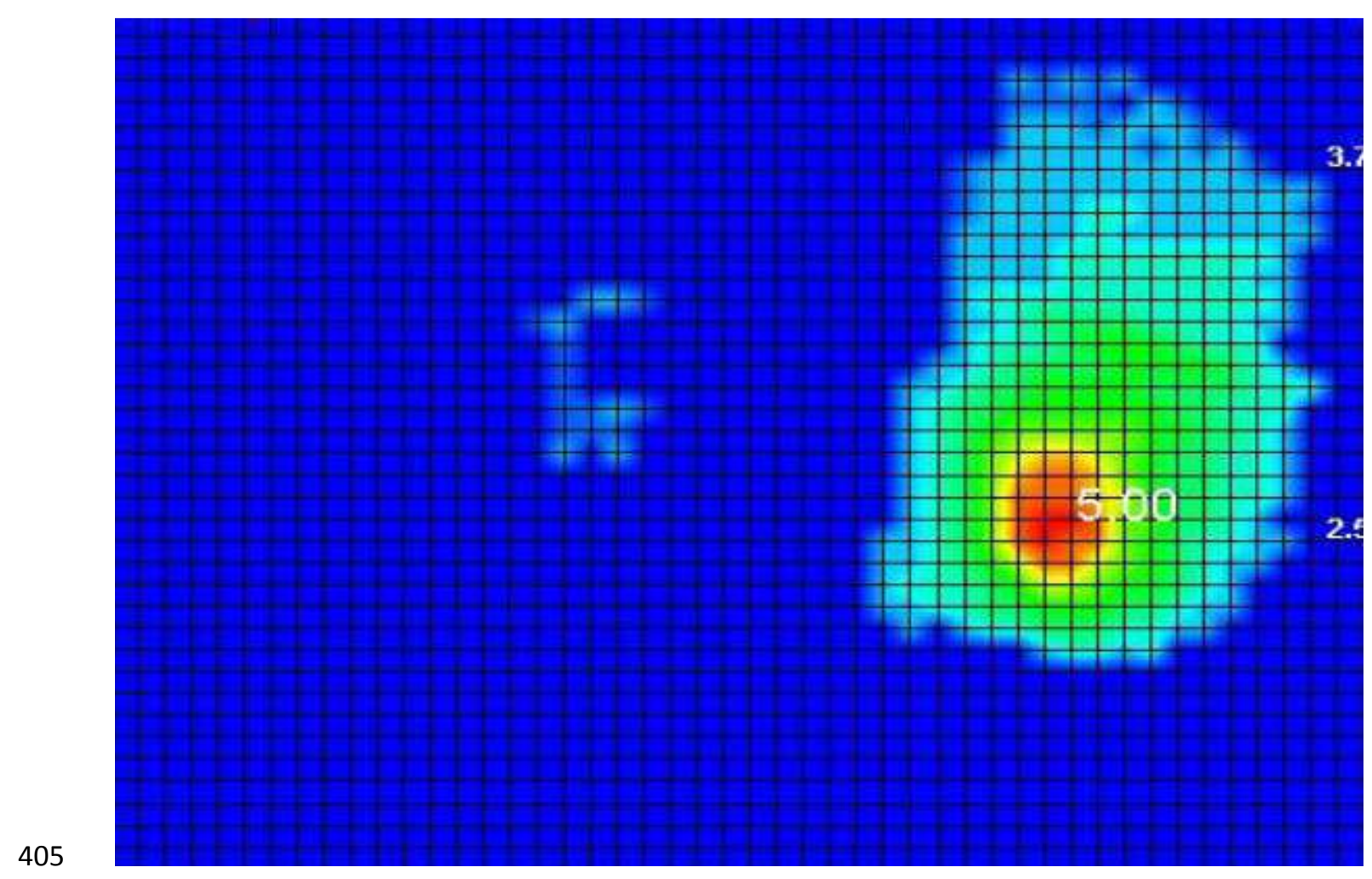

$406 \quad$ Figure 3

407 


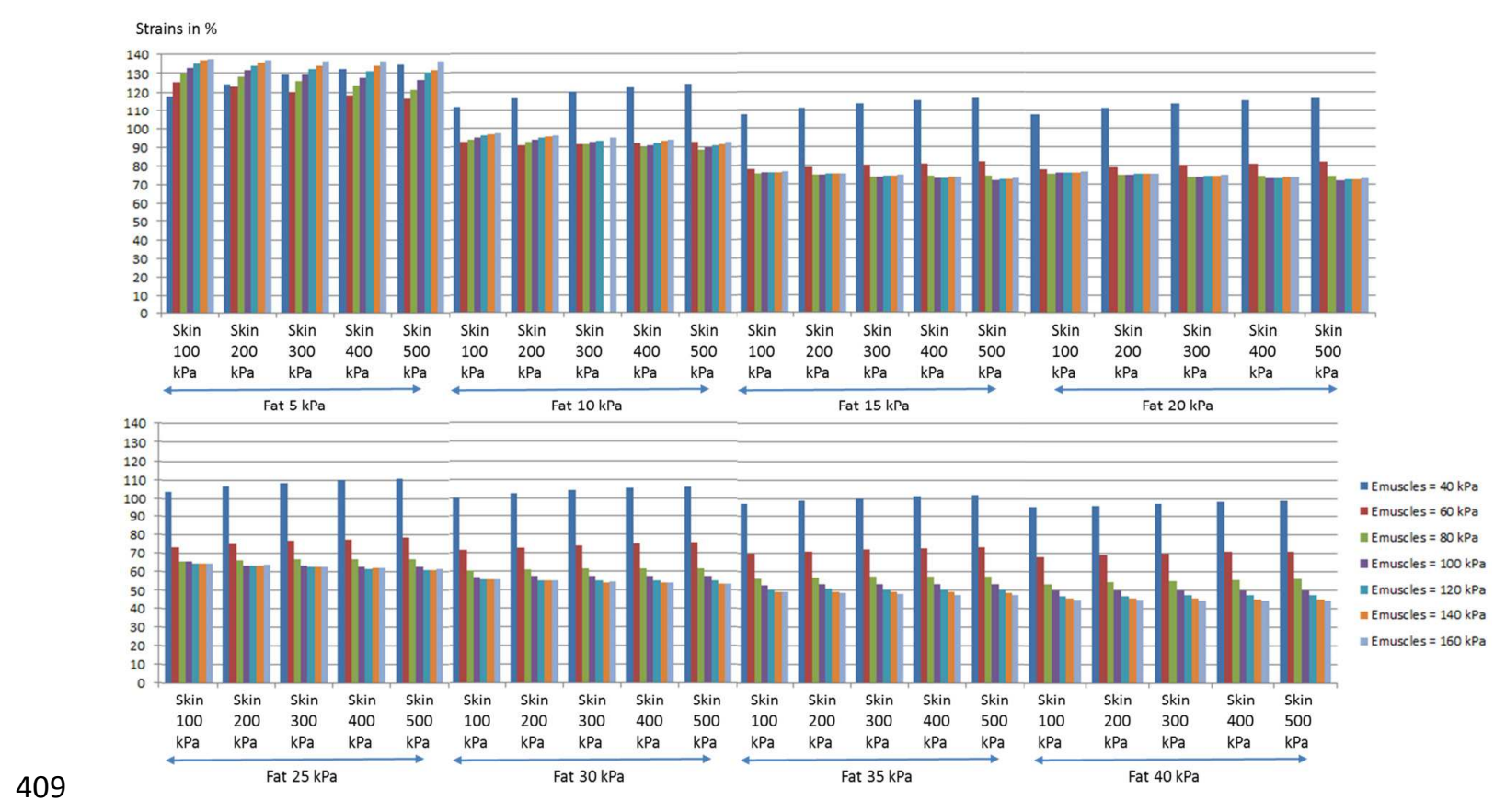

410

Figure 4

411 


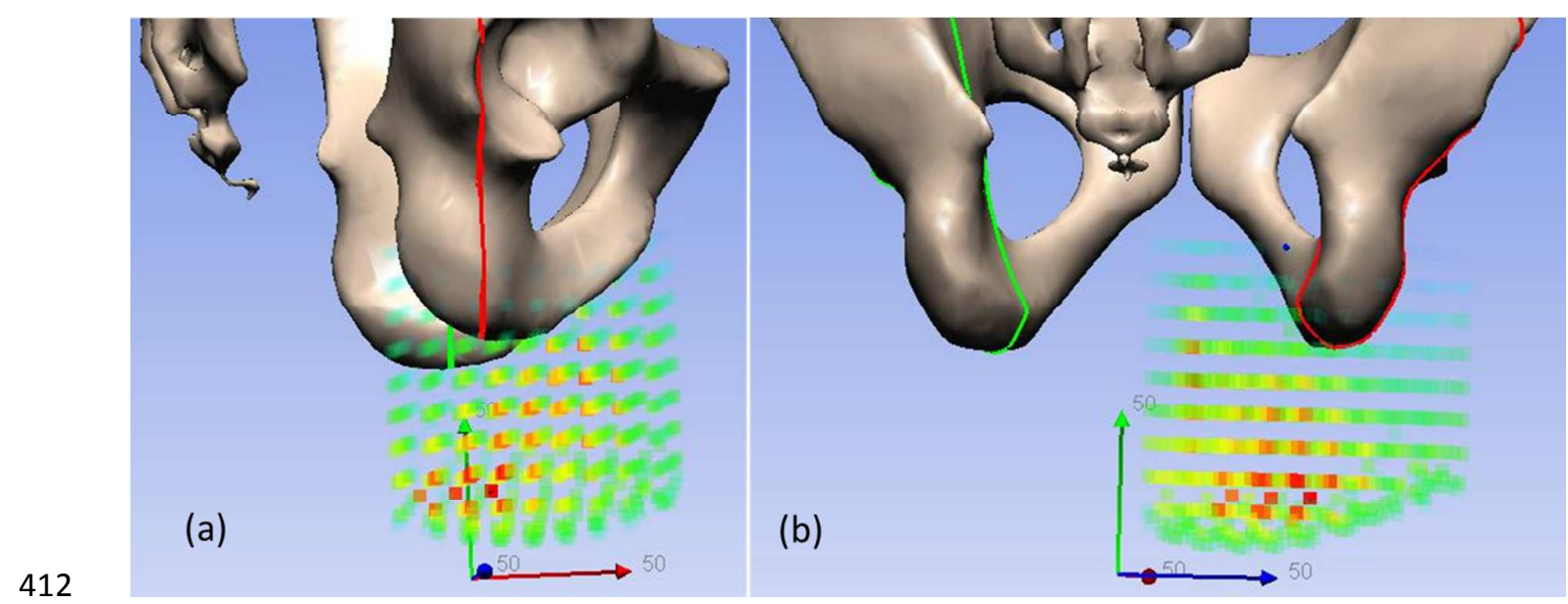

\section{$413 \quad$ Figure 5}

414 